\title{
TINGKAT LITERASI EKONOMI PADA MAHASISWA PROGAM STUDI MANAJEMEN STIE INDONESIA PONTIANAK
}

\author{
Juliahir Barata ${ }^{1^{*}}$, Yuana $^{2}$
}

Sekolah Tinggi Ilmu Ekonomi Indonesia Pontianak ${ }^{12}$

\section{N F O A R T I K E L}

Riwayat Artikel:

Received : May, $15^{\text {th }} 2021$

Revised : June, $4^{\text {th }} 2021$

Accepted : June, $10^{\text {th }} 2021$

\section{Keywords:}

Literacy, economy, students, college of economic science

\section{Kata Kunci:}

Literasi, ekonomi, mahasiswa, sekolah tinggi ilmu ekonomi

\begin{abstract}
A B S T R A C T
The main purpose of this article's research is to describe the level of economic literacy in management students at the Indonesian College of Economic Sciences Pontianak. The research method used by the author is quantitative dexsripfi with data collection instrument in the form of questionnaires. The subject of this study was students of management study program STIE Indonesia Pontianak academic year 2019/2020 which amounted to 221 students. The data analysis uses an average calculation of the total score of questionnaire answers which is then interpreted against the table of economic literacy levels. The main findings of this study are that the level of economic literacy of students of STIE Indonesia Pontianak management study program is in the low category which is reviewed from aspects of literacy that include aspects of the ability to allocate money; financial record skills; knowledge of the benefits of savings; knowledge of debt; knowledge of insurance; decision on replacement of goods; knowledge of investments. The limitation of this study is that it is not able to identify the factors that shape economic literacy
\end{abstract}

\section{A B S T R A K}

Tujuan pokok dari penelitian artikel ini adalah untuk mendeskripsikan tingkat literasi ekonomi pada mahasiswa manajemen di Sekolah Tinggi Ilmu Ekonomi Indonesia Pontianak. Metode penelitian yang digunakan oleh penulis yakni kuantitatif deksripfi dengan instrument pengumpul data berupa angket. Subjek penelitian ini adalah mahasiswa program studi manajemen STIE Indonesia Pontianak tahun akademik 2019/2020 yang berjumlah 221 mahasiwa. Analisa data menggunakan perhitungan rata-rata terhadap total skor jawaban angket yang kemudian diinterpretasikan terhadap tabel tingkat literasi ekonomi. Temuan utama dari penelitian ini yakni tingkat literasi ekonomi mahasiswa program studi manajemen STIE Indonesia Pontianak berada pada kategori rendah yang ditinjau dari aspek-aspek literasi yang mencakup aspek kemampuan mengalokasikan uang; keterampilan catatan keuangan; pengetahuan tentang manfaat tabungan; pengetahuan tentang hutang; pengetahuan tentang asuransi; keputusan penggantian barang; pengetahuan tentang investasi. Keterbatasan penelitian ini yakni tidak mampu mengidentifikasi faktor-faktor pembentuk literasi ekonomi tersebut.

\footnotetext{
${ }^{*}$ Corresponding author :

Address : Pontianak, Kalimantan Barat, Indonesia

E-mail : juliahir@yahoo.com
} 


\section{PENDAHULUAN}

Konsep pokok dari ilmu ekonomi yakni mempelajari cara individu untuk memenuhi segala kebutuhan dan keinginan yang terus bertambah dengan memanfaatkan sumber daya yang tersedia (Susanti, 2017). Individu yang telah mempelajari ilmu ekonomi diharapkan memiliki kecerdasan dalam mengambil keputusan ekonomi. Keputusan ekonomi yang cerdas dapat diukur dari kemampuan mengelola sumber daya yang dimiliki untuk memenuhi kebutuhan dan menciptakan nilai tambah bagi pemenuhan keinginan. Pengambilan keputusan yang cerdas dalam bentuk perilaku ekonomi harus didasari pada literasi ekonomi yang dimiliki setiap individu. Pada prinsipnya literasi ekonomi merupakan alat yang berguna untuk merubah perilaku dari tidak cerdas menjadi cerdas, seperti memanfaatkan pendapatan untuk menabung, berinvestasi, proteksi dan memenuhi kebutuhan hidup (Sina, 2012).

Literasi ekonomi dan pengetahuan tentang mengelola keuangan adalah modal individu untuk mencapai kesejahteraan. Secara ekstrinsik, keduanya dianggap sama, tetapi konstruksi yang melandasinya berbeda. Pengetahuan finansial adalah dimensi integral, tetapi tidak setara dengan, literasi keuangan. Adapun literasi ekonomi memiliki dimensi aplikasi tambahan yang menyiratkan bahwa seseorang harus memiliki kemampuan dan kepercayaan diri untuk menggunakan pengetahuan keuangannya untuk membuat keputusan keuangan (Huston, 2012)

Literasi ekonomi menjadi fondasi dalam pengambilan keputusan keuangan dapat ditingkatkan dengan memberikan informasi berkualitas yang lebih baik kepada individu pengambil keputusan. Penyajian informasi ini harus dilakukan secara non-kompleks melalui lingkungan kelembagaan kondusif serta terstruktur sehingga mampu menginternalisasi informasi dari sumber eksternal. Internalisasi informasi ini akan menunjang pengambilan keputusan ekonomi secara efektif dan efisien termasuk dalam hal investasi keuangan dan keputusan untuk berhutang (Altman, 2012; Ibrahim \& Alqaydi, 2013; van Rooij et al., 2011).

Lingkungan kelembagaan sebagai medium peningkatan literasi ekonomi individu dapat berupa lembaga pendidikan formal yang memiliki struktur kurikulum yang jelas dan terukur, salah satunya adalah perguruan tinggi khusus bidang ilmu ekonomi. Perguruan tinggi diharapkan dapat mendorong individu yang menempuh pendidikan di kampus (mahasiswa) untuk melek ekonomi melalui mata kuliah serta penyelengaraan kegiatan yang berkaitan dengan literasi ekonomi. Mahasiswa yang mempunyai tingkat literasi ekonomi yang baik akan mampu mempersiapkan diri untuk kesejahteraan hidup di masa akan datang (Akmal \& Saputra, 2016).

Perguruan Tinggi harus dapat memberikan pendidikan tentang personal finance kepada mahasiswanya. Hal ini agar mahasiswa sejak dini memiliki pengetahuan tentang keuangan pribadi agar mereka bisa menjadi mahasiswa yang cerdas, bisa mengatur keuangan dengan baik, dan bisa memiliki kehidupan yang sejahtera serta tidak mengalami kesulitan keuangan di masa depan (Margaretha \& Pambudhi, 2015). Oleh karena itu, pembelajaran di perguruan tinggi harus dapat berpengaruh langsung terhadap literasi finansial aspek kognitif dan aspek sikap mahasiswa (Widyawati, 2012).

Fenomena di lapangan menunjukkan bahwa semakin tinggi tingkat pendapatan yang diterima mahasiswa maka semakin tinggi pula keinginan untuk membelanjakan uang tersebut. Keinginan mahasiswa dalam membelanjakan pendapatan yang diterima tanpa mengontrol keuangan dapat menyebabkan kegagalan dalam mengelola keuangan dan berdampak menurunnya tingkat literasi keuangan. Hal ini disebabkan oleh gaya hidup mahasiswa yang konsumtif dan pergaruh dalam pergaulan sehari-hari (Susanti, 2017). Oleh karena itu, pendidikan di kampus harus mampu menanamkan literasi ekonomi yang baik pada mahasiswa. Literasi ekonomi yang tinggi juga berfungsi untuk mengantisipasi perilaku 
pembelian impulsive (spontan) pada mahasiswa karena literasi ekonomi akan memberikan mereka ilmu mengenai cara mengelola keuangan untuk kepentingan berkonsumsi (Pratiwi, 2017). Semakin tinggi kemampuan literasi ekonomi mahasiswa maka tingkat perilaku konsumtif akan semakin menurun. Sebaliknya jika literasi ekonomi mahasiswa rendah maka tingkat perilaku konsumtif mahasiswa meningkat (Kanserina, 2015). Literasi ekonomi merupakan pondasi yang dapat membentuk perilaku keuangan yang baik. Perilaku keuangan yang baik dapat ditunjukkan melalui keputusan-keputusan keuangan yang diambil secara tepat serta menghargai nilai dari uang. Peningkatan literasi ekonomi akan mengarahkan mahasiswa untuk rasional dalam perilaku konsumtif (Solihat \& Arnasik, 2018).

Kondisi ini juga terjadi pada mahasiswa Sekolah Tinggi Ilmu Ekonomi (STIE) Indonesia Pontianak. Berdasarkan pengamatan dan wawancara awal yang dilakukan penulis, beberapa mahasiswa tidak memiliki perencanaan yang baik terhadap pengelolaan finansial mereka yang berdampak pada tidak terpenuhinya beberapa kebutuhan akibat terlalu besar pengeluaran pada aspek keinginan. Padahal, para mahasiswa ini sudah dibekali dengan berbagai teori ekonomi sejak awal perkuliahan.

Berdasarkan kajian terhadap beberapa kajian dan fenomena di atas, maka penulis merasa tertarik untuk melakukan kajian tentang tingkat literasi mahasiswa di Sekolah Tinggi Ilmu Ekonomi (STIE) Indonesia Pontianak. Ketertarikan ini didasari pada rasa ingin tahu yang besar tentang proses internalisasi materi-materi kuliah oleh mahasiswa STIE Indonesia Pontianak dalam implikasi kegiatan ekonomi mereka sehari-hari. Penelitian ini diharapkan dapat bermanfaat secara teoritis dan praktis bagi penulis, mahasiswa dan institusi..

\section{KAJIAN PUSTAKA}

Melek ekonomi adalah kemampuan untuk menggunakan konsep ekonomi untuk membuat keputusan tentang penghasilan, tabungan, pengeluaran dan mengalokasikan uang. Hal ini diperjelas oleh pendapat dari Organization for Economic Literacy (OEL) yang menegaskan bahwa melek ekonomi tidak hanya meliputi pemahaman konsep dasar ekonomi dan fakta ekonomi, tetapi juga tentang kemampuan berpikir kritis yang mendukung cara berpikir ekonomi yang benar. Dengan kata lain, melek ekonomi melibatkan pengetahuan dan penerapan 19 teori-teori ekonomi yang mendasar dalam mengambil keputusan tentang sumber daya yang terbatas (Pandey \& Bhattacharya, 2012).

Kriteria Economic literacy menurut NCEE (The national Council on Economic Education) tahun 2003 terdiri dari 20 indikator : 1) Mampu menganalisis perubahan permintaan barang; 2) Mampu mengelola peran wirausaha; 3) Mampu menganalisis tingkat harga terhadap kecenderungan menabung; 4) Mampu mengalokasikan pendapatan individu; 5) Mampu mengalokasikan pendapatan nasional; 6) Mampu manganalisis perubahan penawaran dan permintaan; 7) Mampu menganalisis dampak kebijakan perdagangan internasional; 8) Mampu menganalisis dampak kebijakan pemerintah terhadap penetapan harga; 9) Mampu menjelaskan peran pelaku ekonomi, produsen, konsumen dalam pemerintahan dan perekonomian; 10) Mampu menjelaskan manfaat dari perdagangan internasional; 11) Mampu menganalisis dampak perubahan permintaan dan penawaran terhadap harga barang; 12) Mampu menjelaskan penggunaan sumber daya yang terbatas; 13) Mampu menjelaskan peran pasar modal dalam perekonomian; 14) Mampu menganalisis cost dan benefit dari transaksi ekonomi; 15) Mampu menganalisis cost dan benefit dari pengambilan keputusan; 16) Mampu menjelaskan peran pemerintah dalam perekonomian; 17) Mampu menjelaskan Anggaran Perencanaan Belanja Negara; 18) Mampu menganalisis dampak inflasi; 19) Mampu menganalisis pengembangan industry; 20) Mampu menjelaskan bunga uang (Sina, 2012). 
Otoritas Jasa Keuangan Indonesia (2020) menjelaskan terdapat tingkatan literasi keuangan seseorang yang diklasifikasikan menjadi beberapa jenis tingkat, antara lain yaitu: 1) Well Literate. Pada tahap ini, seseorang yang mempunyai pengetahuan dan keyakinan tentang lembaga jasa keuangan dan juga produk atau jasa keuangan, termasuk fitur, manfaat dan risiko, hak dan kewajiban terkait produk dan jasa keuangan serta juga mempunyai keterampilan dalam memakai produk dan jasa keuangan. 2) Suff Literate. Pada tahap ini, seseorang mempunyai pengetahuan dan keyakinan tentang lembaga jasa keuangan dan juga produk dan jasa keuangan termasuk fitur, manfaat dan risiko, hak dan kewajiban terkait produk dan jasa keuangan. 3) Less Literate. Pada tahap ini, seseorang hanya mempunyai pengetahuan tentang lembaga jasa keuangan, produk dan jasa keuangan. 4) Not Literate. Pada tahap ini, seseorang tidak mempunyai pengetahuan dan keyakinan tentang lembaga jasa keuangan dan juga produk serta jasa keuangan, serta tidak mempunyai keterampilan dalam memakai produk dan jasa keuangan (ojk.go.id).

Beberapa riset terdahulu memberikan kesimpulan berbeda. Riset Herawati menunjukkan bahwa pembelajaran di perguruan tinggi tidak berkontribusi secara signifikan terhadap perilaku keuangan mahasiswa (Herawati, 2015). Demikian pula dengan hasil riset Nidar, bahwa tingkat literasi keuangan pribadi mahasiswa di Universitas Padjadjaran masuk dalam kategori rendah, dan karenanya perlu ditingkatkan, terutama untuk bidang: investasi, kredit, dan asuransi (Nidar \& Bestari, 2012). Menurut Rasyid, kurangnya literasi keuangan mahasiswa dapat disebabkan karena belum tersedianya kurikulum akademik tentang pendidikan personal finance bagi mahasiswa, sehingga terlihat dari sikap mahasiswa yang belum disiplin, belum bertanggungjawab, dan belum konsisten menggunakan uang (Rasyid, 2012). Adapun riset Sabri menambahkan bahwa pengaruh pengalaman konsumen masa kanak-kanak, kurangnya sosialisasi manfaat tabungan dan masalah keuangan rumah tangga yang terjadi pada sebelum mereka kuliah dapat menciptakan kebiasaan buruk terhadap manajemen keuangan (Sabri \& MacDonald, 2010).

\section{METODA PENELITIAN}

Pendekatan yang digunakan dalam penelitian ini yakni kuantitatif deskriptif. Konsep kuantitatif karena penulis ingin menguji teori yang telah ada sebelumnya dengan kondisi di lapangan. Pendekatan ini digunakan karena penulis bermaksud mendeskripsikan temuan penelitian berdasarkan data yang telah dikumpulkan dan diolah secara matematis (Sugiyono, 2011).

Subjek penelitian ini adalah seluruh mahasiswa STIE Indonesia Pontianak Program Studi Manajemen yang terdaftar secara administratif pada tahun akademik 2019/2020 yakni sebanyak 625 orang (sumber: forlap.kemdikbud.go.id). Mengingat keterbatasan penulis dan telah terpenuhinya kaidah ilmiah tentang jumlah minimum subjek penelitian yang dapat ditarik sampel maka sampel penelitian ini sebanyak 221. Jumlah tersebut diperoleh dari tabel penentuan jumlah sampel yang dikembangkan oleh Isaac and Michael dengan tingkat kesalahan 5\% (Sugiyono, 2011).

Teknik pengumpulan data primer terhadap sampel penelitian yakni menggunakan metode Survey. Adapun alat untuk mengumpulkan data menggunakan instrument angket yang memuat pertanyaan terkait literasi ekonomi mahasiswa (Sugiyono, 2011). Setelah data terkumpul, maka penulis menghitung nilai rata-rata tingkat literasi ekonomi mahasiswa dengan menggunakan rumus:

$$
\text { Indeks }=\frac{\Sigma f x}{N} \times 100 \%
$$

(Sumber: Sugiyono, 2011) 
Setelah diketahui nilai rata-rata literasi ekonomi masyarkat, selanjutnya akan dibandingkan dengan tabel berikut:

Tabel 1. Kategori Tingkat Literasi Ekonomi

\begin{tabular}{ll}
\hline Rentang Indeks & Kategori \\
\hline $76-100 \%$ & Tinggi/ Well Literate \\
\hline $51-75 \%$ & Sedang/ Suff Literate \\
\hline $26-50 \%$ & Rendah/ Less Literate \\
\hline $1-25 \%$ & Sangat Rendah/ Not Literate
\end{tabular}

(Sumber: OJK, 2014)

\section{ANALISIS DAN PEMBAHASAN Analisis Data}

Hasil survey diperoleh menggunakan media google form karena situasi perkuliahan masih menggunakan sistem dalam jaringan (daring) akibat Pandemi Covid-19. Data yang disajikan terlebih dahulu yakni demografi responden yang terbagi menjadi jenis kelamin, tempat tinggal selama kuliah dan pendapatan setiap bulan yang diperoleh dari pemberian orang tua maupun hasil bekerja selama kuliah.

Tabel 2. Deskripsi Data Berdasarkan Demografi

\begin{tabular}{|c|c|}
\hline Aspek & Persentase \\
\hline \multicolumn{2}{|l|}{ Jenis Kelamin: } \\
\hline - $\quad$ Laki-Laki & $37,5 \%$ \\
\hline - $\quad$ Perempuan & $62,5 \%$ \\
\hline \multicolumn{2}{|l|}{ Tempat Tinggal } \\
\hline - $\quad$ Rumah Orang Tua & $58,1 \%$ \\
\hline - $\quad$ Rumah Kerabat/ Keluarga & $19,9 \%$ \\
\hline - $\quad$ Indekost & $22,1 \%$ \\
\hline \multicolumn{2}{|l|}{ Pendapatan / Uang Kiriman Setiap Bulan } \\
\hline - $\quad 0$ - Rp.499.000 & $39,3 \%$ \\
\hline - $\quad$ Rp.500.000 - Rp.999.000 & $23,7 \%$ \\
\hline - $\quad$ Rp.1.000.000 - Rp.1.999.000 & $16,3 \%$ \\
\hline - $\quad>$ Rp.2.000.000 & $20,7 \%$ \\
\hline
\end{tabular}

Penyajian data demografi dimaksudkan untuk mendeskripsikan kondisi mahasiswa STIE Indonesia Pontianak yang menjadi responden dalam penelitian ini.

Tabel 3. Persentase Jawaban Angket

\begin{tabular}{lc}
\hline \multicolumn{1}{c}{ Aspek } & Skor \\
\hline Kemampuan mengalokasikan uang & 1839 \\
\hline Keterampilan catatan keuangan & 1449 \\
\hline Pengetahuan tentang manfaat tabungan & 1449 \\
\hline Pengetahuan tentang hutang & 822 \\
\hline Pengetahuan tentang asuransi & 1254 \\
\hline Keputusan penggantian barang & 822 \\
\hline Pengetahuan tentang investasi & 1881 \\
\hline \multicolumn{1}{c}{ Total } & 9516 \\
\hline
\end{tabular}


Total skor kemudian dibagi dengan jumlah responden untuk mengetahui skor rata-rata:

$$
\text { Indeks }=\frac{9516}{221} \times 100 \%=43,05 \%
$$

Hasil rata-rata persentase skor tersebut diinterpretasikan terhadap tabel yang dikembangkan dari standar OJK sehingga dapat dinyatakan bahwa tingkat literasi ekonomi mahasiswa STIE Indonesia Pontianak berada pada kategori Rendah/ Less Literate.

\section{Pembahasan}

Berdasarkan hasil analisa terhadap rekapitulasi jawaban angket mahasiswa, diketahui bahwa tingkat literasi ekonomi mahasiswa STIE Indonesia Pontianak secara umum masih berkategori rendah. Adapun penjabaran setiap aspek penelitian, sebagai berikut:

Aspek penelitian pertama yakni kemampuan mahasiswa dalam mengalokasikan uang. Aspek ini terdiri atas lima pertanyaan tentang rencana pembelian barang/jasa oleh mahasiswa. Hasil jawaban angket menunjukkan bahwa umumnya mahasiswa hanya mengalokasikan pendapatan yang mereka peroleh untuk kebutuhan dasar seperti kebutuhan pangan dan membayar sewa rumah. Sedangkan kebutuhan yang dianggap kecil seringkali tidak terencana (pembelian spontan) seperti kuota internet, berbelanja di café atau warung kopi, perawatan diri dan pembelian bahan bakar.

Aspek kedua yakni keterampilan mencatat setiap pengeluaran, yang terdiri atas tiga pertanyaan tentang kebiasaan mahasiswa mencatat uang yang mereka terima dan belanjakan. Analisa terhadap rekapitulasi angket menunjukkan bahwa aspek ini hanya dilakukan oleh sebagian kecil responden dengan karakteristik utama bahwa responden tersebut merupakan mahasiswa rantau dengan pendapatan sekitar Rp.500.000 perbulan. Responden yang memiliki pendapatan di atas nomimal tersebut dan responden yang tinggal dengan orang tua, umumnya tidak mencatat pengeluaran / belanja.

Rekapitulasi angket tentang kebiasaan dan pengetahuan atas manfaat tabungan juga masuk kategori rendah. Responden menganggap bahwa tabungan sulit dilakukan karena semua pendapatan yang mereka peroleh, pasti dibelanjakan sampai habis di bulan yang sama. Responden memiliki pengetahuan yang cukup tentang manfaat menabung, namun demikian mereka tidak terampil melaksanakannya. Responden yang merupakah mahasiswa rantau memang memiliki tabungan, namun hanya digunakan untuk media pengiriman uang dari orang tuanya.

Aspek keempat yakni pengetahuan tentang hutang. Pada aspek ini umumnya responden setuju untuk menghindari hutang karena menimbulkan rasa khawatir dan malu terhadap rekan-rekannya. Responden memilih untuk menunda keinginan untuk berbelanja jika memang tidak memiliki uang daripada harus berhutang.

Aspek pengetahuan tentang asuransi juga masuk kategori rendah. Responden paham tentang manfaat asuransi, namun enggan untuk mendaftarkan diri sebagai nasabah asuransi. Umumnya asuransi yang mereka miliki hanya asuransi kesehatan yang dikeluarkan oleh pemerintah yakni BPJS.

Pada aspek keputusan penggantian barang jika hilang atau rusak, responden setuju atas opsi mencoba memperbaiki terlebih dahulu jika barang tersebut rusak, atau menunda pembelian jika barang tersebut hilang. Keputusan ini didasari pada kesadaran kondisi ekonomi orang tua. 
Aspek pengetahuan tentang investasi pada mahasiswa STIE Indonesia Pontianak sudah sangat baik. Rekapitulasi jawaban angket menunjukkan bahwa mahasiswa memiliki kesadaran akan pentingnya memiliki investasi bagi kesejahateraan.

Hasil riset ini mendukung beberapa hasil kajian empiris yang telah dilaksanakan oleh beberapa peneliti seperti yang telah diungkapkan pada bagian sebelumnya. Kondisi ini patut menjadi catatan bersama terkait proses pembelajaran dan internalisasi pengetahuan ekonomi pada mahasiswa yang menempuh pendidikan tinggi di jurusan ekonomi dan serumpunnya.

\section{SIMPULAN, KETERBATASAN DAN SARAN}

Simpulan yang dapat ditarik dari hasil penelitian di atas bahwa tingkat literasi ekonomi pada mahasiswa Sekolah Tinggi Ilmu Ekonomi Indonesia Pontianak menempati kategori rendah/ less literate. Tingkat literasi ekonomi ini diperoleh dari hasil analisa terhadap rekapitulasi jawaban angket yang mencakup aspek kemampuan mengalokasikan uang; keterampilan catatan keuangan; pengetahuan tentang manfaat tabungan; pengetahuan tentang hutang; pengetahuan tentang asuransi; keputusan penggantian barang; pengetahuan tentang investasi.

Keterbatasan dalam penelitian ini yakni peneliti hanya mengukur tingkat literasi ekonomi mahasiswa tanpa mendalami faktor-faktor pembentuk tingkat literasi tersebut. variabel ini dapat menjadi bahan kajian selanjutnya.

Saran yang dapat penulis sampaikan kepada institusi agar dapat melakukan evaluasi kurikulum dan monitoring proses pembelajaran. Saran kepada mahasiswa, hendaknya proses perkuliahan dapat diikuti dengan serius sehingga informasi yang diperoleh di ruang kuliah dapat terserap dan diaplikasikan dalam kehidupan sehari-hari.

\section{DAFTAR PUSTAKA}

Akmal, H., \& Saputra, Y. E. (2016). Analisis Tingkat Literasi Keuangan. Jurnal Ekonomi Dan Bisnis Islam, 1(2), 235-244.

Altman, M. (2012). Implications of behavioural economics for financial literacy and public policy. The Journal of Socio-Economics, 41(5), 677-690. https://doi.org/10.1016/j.socec.2012.06.002

Herawati, N. T. (2015). Kontribusi pembelajaran di perguruan tinggi dan literasi keuangan terhadap perilaku keuangan mahasiswa. Jural Pendidikan Dan Pengajaran, 1-3(48), 60 70. https://doi.org/https://dx.doi.org/10.23887/jppundiksha.v48i1-3.6919

Huston, S. J. (2012). Financial literacy and the cost of borrowing. International Journal of Consumer Studies, 36(5), 566-572. https://doi.org/10.1111/j.1470-6431.2012.01122.x

Ibrahim, M. E., \& Alqaydi, F. R. (2013). Financial Literacy, Personal Financial Attitude, and Forms of Personal Debt among Residents of the UAE. International Journal of Economics and Finance, 5(7). https://doi.org/10.5539/ijef.v5n7p126

Kanserina, D. (2015). Perilaku Konsumtif Mahasiswa Jurusan Pendidikan Ekonomi UNDIKSHA 2015. Jurnal Pendidikan Ekonomi Undiksha, 5(1).

Margaretha, F., \& Pambudhi, R. A. (2015). Tingkat Literasi Keuangan pada Mahasiswa S-1 Fakultas Ekonomi. Jurnal Manajemen Dan Kewirausahaan (Journal of Management and Entrepreneurship), 17(1), 76-85. https://doi.org/10.9744/jmk.17.1.76-85

Nidar, S. R., \& Bestari, S. (2012). Personal Financial Literacy Among University Students (Case Study at Padjadjaran University Students, Bandung, Indonesia). World Journal of Social Sciences, 2(4), 162-171.

Pandey, C., \& Bhattacharya. (2012). Economic Literacy of Senior Secondary School 
Teachers: A Field Study. Journal of All India Association for Educational Research, 24(1). Pratiwi, I. (2017). Pengaruh Literasi Ekonomi, Kelompok Teman Sebaya dan Kontrol Diri Terhadap Perilaku Pembelian Impulsif untuk Produk Fashion di Online Shop pada Mahasiswa Jurusan Pendidikan Ekonomi UNDIKSHA. Jurnal Pendidikan Ekonomi Undiksha, 9(1), 98-108. https://doi.org/10.23887/jjpe.v9i1.19994

Rasyid, R. (2012). Analisis Tingkat Literasi Keuangan Mahasiswa Program Studi Manajemen Fakultas Ekonomi Universitas Negeri Padang. Jurnal Kajian Manajemen Bisnis, 1(2), 91-106.

Sabri, M. F., \& MacDonald, M. (2010). Savings Behavior and Financial Problems among College Students: The Role of Financial Literacy in Malaysia | Sabri | Cross-cultural Communication. Crosscultural Communication, 6(3), P103-110. https://doi.org/10.3968/j.ccc.1923670020100603.009

Sina, P. G. (2012). Analisis Literasi Ekonomi. Jurnal Economia, 8(2), 135-143. https://doi.org/10.21831/economia.v8i2.1223

Solihat, A. N., \& Arnasik, S. (2018). Pengaruh Literasi Ekonomi Terhadap Perilaku Konsumtif Mahasiswa Jurusan Pendidikan Ekonomi Universitas Siliwangi. OIKOS Jurnal Kajian Pendidikan Ekonomi Dan Ilmu Ekonomi, 2(1), 1-13. https://doi.org/10.23969/oikos.v2i1.915

Sugiyono. (2011). Metode Penelitian Kuantitatif Kualitatif dan R\&D (14th ed.). Alfabeta.

Susanti, S. (2017). Pengaruh Locus of Control Internal Dan Pendapatan Terhadap Literasi Keuangan Mahasiswa. Jurnal Ekonomi Pendidikan Dan Kewirausahaan, 4(1), 5. https://doi.org/10.26740/jepk.v4n1.p5-17

van Rooij, M., Lusardi, A., \& Alessie, R. (2011). Financial literacy and stock market participation. Journal of Financial Economics, 101(2), 449-472. https://doi.org/10.1016/j.jfineco.2011.03.006

Widyawati, I. (2012). Faktor-Faktor yang Mempengaruhi Literasi Finansial Mahasiswa Fakultas Ekonomi dan Bisnis Universitas Brawijaya. Assets: Jurnal Akuntansi Dan Pendidikan, 1(1), 89. https://doi.org/10.25273/jap.v1i1.527

www.ojk.go.id/tingkatliterasiekonomi/diakses pada tanggal 2 februari 2020 